\title{
Research for the Influence of Distribution Network Line Reclosing Current on Line Protection
}

\author{
YU Kansheng ${ }^{1, a}$, WU Ying ${ }^{2}$, FAN Ruixiang ${ }^{1}$, PAN Benren ${ }^{1}$, CAO Bei ${ }^{1}$ \\ ${ }^{1}$ Jiangxi Electric Power Research Institute, 330096 Nanchang ,China \\ 2 Jiangxi Electric Power CO. Maintenance Branch,330096 Nanchang, China
}

\begin{abstract}
According to the distribution network line structure and reclosing control strategy, the system simulation model of distribution network lines has established based on the realtime digital simulation RTDS. Based on this, distribution network switching impulse current characteristic has researched with different capacity, different distribution and different load power factor under the different voltage switching angles. The results of the study provide a scientific basis for distribution network line protection setting, in order to further lay the foundation for improvement the validity and reliability of distribution network line protection action.
\end{abstract}

\section{Introduction}

With the continuous random access of residential load and commercial unit into distribution network, the load current of distribution network increases constantly. Meanwhile, grid-connected operation of new distribution transformers which come into service recently has to some extent changed the system structure and power flow distribution. Therefore, a higher demand of safe and reliable operation of power network protection and control equipment is proposed. For example, the reclosing impact current of distribution network line will change, and the amplitude and fall time of impact current will change to a certain extent[1,2]. Post- acceleration protection setting of distribution network was studied deeply and comprehensively in literatures [3-5], however, only the determination of postacceleration protection set point is studied from the single aspect of setting calculation, but the calculation did not involve the distribution situation of distribution transformer capacity of distribution line, as well as the parameters and load character of distribution line. Obviously, the accuracy level of post-acceleration protection set point of setting is poor, which then lead to the reduction of the success rate of reclosing of distribution line.

The establishment of technology test platform for distribution network line based on real-time digital simulation technology and line protective device is an efficient way to solve above problem[6]. In this paper, $10 \mathrm{kV}$ system distribution line is taken as research object, a distribution line real-time simulation platform based on RTDS is established, and on this bases, the characteristics of closing impact current of distribution line under different distribution of distribution transformer capacity, different load power factor of low voltage side of the distribution transformer and different voltage

\footnotetext{
${ }^{a}$ Corresponding author : 249245208@qq.com

(C) The Authors, published by EDP Sciences. This is an open access article distributed under the terms of the Creative Commons Attribution License 4.0 (http://creativecommons.org/licenses/by/4.0/).
} 
closing angle is studied, and the main factors which influence the characteristics of closing impact current is sorted out.

\section{Real-time Simulation Model of Distribution Line Simulation}

\subsection{Modular Design of Real-time Simulation}

RTDS model includes $110 \mathrm{kV}$ infinity system model, $110 \mathrm{kV}-10 \mathrm{kV}$ step-down transformer model, $10 \mathrm{kV}$ switch model, $10 \mathrm{kV}$ distribution network line model, $10 \mathrm{kV}$ transformer model and $0.4 \mathrm{kV}$ low voltage load model. When modeling, simulation precision requirement of single transformer's magnetizing rush current should be met, meanwhile, limits on the number of compute nodes by hardware of simulation system should be considered. Therefore, it is best to use the modularized design method, and to optimize the allocation of RTDS processor cards.

\subsection{Modeling Progress of RTDS}

Real-time simulation modeling of distribution network lines can be divided into four parts: main loop of the distribution network wiring system, breaker analog output model, breaker digital input and output model, and fault control strategy model.Main loop of the distribution network wiring system uses infinite power to replace $110 \mathrm{kV}$ power network system. The control strategy model is established according to corresponding expressions and control structure diagram and based on the component model library of RTDS control system.

\section{Field Measurement Experiment of Distribution Transformer}

\subsection{Modular Design of Real-time Simulation}

In the analysis of the influence from distribution network line reclosing impact current to the line protection, two important parameters should be mainly considered, which are over current ration in acceleration section and delay time ration of independent setting in acceleration section. In simulation modeling, the lines and transformer model which determine the current current ration can be built correctly, but fall time of distribution transformer magnetizing rush current, which is related to time setting of protection in acceleration section, is unable to be obtained from known parameters of distribution transformer. It is required to measure the distribution transformer on field to obtain the fall time of magnetizing rush current and achieve the parameter identification of distribution transformer in simulation experiment. In the experiment, the field measurement is according to capacity of $4 \mathrm{MW}, 8 \mathrm{MW}$ and $10 \mathrm{MW}$. The constant identification[7] of fall time of distribution transformer is approximated as 0.3 .
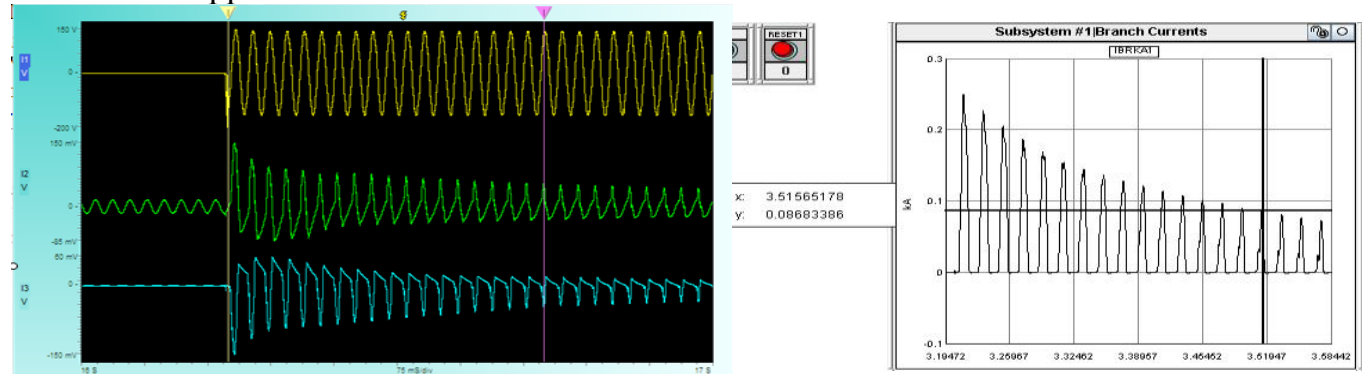

Figure 1.Distribution transformer no-load test(Left is measured waveform, right is simulation waveform)

\section{Research on Real-time Simulation Experiment}




\subsection{Scheme on Real-time Simulation Test}

To research the influence of distribution network line's transformer capacity, distribution, load power factor and closing angel to distribution network line closing impact current, bracketing method is used in the real-time simulation experiment, as shown in Table 1, where:

Table 1. Table of experimental factors

\begin{tabular}{|c|c|c|c|c|}
\hline Closing angle $\left(^{\circ}\right)$ & 0 & 30 & 60 & 90 \\
\hline Load power factor & 0.5 & 0.6 & 0.75 & No-load \\
\hline Total capacity of distribution transformer(MVA) & 4 & 8 & & \\
\hline Distribution of distribution transformers & "136" & "334" & "631" & \\
\hline
\end{tabular}

(1) "136" denotes that the distribution of transformers of distribution network line is roughly that the transformer capacity close to exit section (forepart) of transformer substation is low, the capacity of distribution transform at end of line is high, and the capacity of distribution transform at mid-piece of line is between two parties.

(2) "334" denotes that the distribution of capacity of distribution transform at exit section of transformer substation, mid-piece and end of line is uniform.

(3) "631" denotes that the distribution of transformers of distribution network line is roughly that the transformer capacity close to exit section (forepart) of transformer substation is high, the capacity of distribution transform at end of line is low, and the capacity of distribution transform at mid-piece of line is between two parties.

\subsection{Real-time Simulation Analysis}

\subsubsection{Characteristic analysis of distribution network line no-load closing impact current}

In the simulation, the total capacity of distribution transformer is 8MVA, and after cutting of the switch while short circuit fault happens, the residual magnetic of distribution transformer is kept in a low level, the experiment data are shown in Table 2. Table 2 shows that under same closing angle, different distribution will lead to different closing impact current, and the higher capacity away from power side (outlet switch of transformer substation), the higher closing impact current is. For same distribution, the amplitude of closing impact current is different under different closing angle. The amplitude of closing impact current decreases with increase of closing angle, and the amplitude of closing impact current is maximum when $0^{\circ}$.

Table 2. The maximum peak of no-load current

\begin{tabular}{|c|c|c|c|}
\hline Impact current(A) & "136" & "334" & "631" \\
\hline $0^{\circ}$ & 447.77 & 687.64 & 1017.9 \\
\hline $30^{\circ}$ & 437.87 & 723.79 & 997.12 \\
\hline $60^{\circ}$ & 356.16 & 596.61 & 849.52 \\
\hline $90^{\circ}$ & 153.98 & 267.87 & 368.86 \\
\hline
\end{tabular}

\subsubsection{Characteristic analysis of impact current under different power factor and load feature}

In the simulation, the total capacity of distribution transformer is 8MVA, and the distribution is "334", the experiment data are shown in Table 3. Table 3 shows that, considering the error of simulation, under same closing angle, the amplitude of impact current under different distribution, same capacity load and different power factor keeps essentially constant. It can be confirmed that under same load capacity, different power factor will not cause large change of amplitude of closing impact current. 
Table 3. The maximum peak of current under different power factor

\begin{tabular}{|c|c|c|c|}
\hline $\begin{array}{c}\text { Impact current } \\
(\mathrm{A})\end{array}$ & $\begin{array}{c}\text { Power factor is } \\
0.5\end{array}$ & $\begin{array}{c}\text { Power factor is } \\
0.6\end{array}$ & $\begin{array}{c}\text { Power factor is } \\
0.75\end{array}$ \\
\hline $0^{\circ}$ & 649.12 & 618.67 & 608.98 \\
\hline $30^{\circ}$ & 569.92 & 566.46 & 529.41 \\
\hline $60^{\circ}$ & 437.12 & 434.58 & 405.92 \\
\hline $90^{\circ}$ & 363.37 & 367.67 & 338.48 \\
\hline
\end{tabular}

\subsubsection{Characteristic analysis of impact current under different distribution of distribution transformers}

In the simulation, the total capacity of distribution transformer is $8 \mathrm{MVA}$, and the power factor is 0.5 , the experiment data are shown in Table 4. Table 4 shows that under same closing angle and different distribution of distribution transformers, the closing impact current is different. The characteristic is represented as that under the same closing angle, the higher distribution transformer capacity away from power side, the higher closing impact current is.

Table 4. The maximum peak of current under different distribution

\begin{tabular}{|c|c|c|c|}
\hline Impact current(A) & $" 136 "$ & $" 334 "$ & $" 631 "$ \\
\hline $0^{\circ}$ & 649.12 & 1000.34 & 1357.55 \\
\hline $30^{\circ}$ & 569.92 & 848.22 & 1224.90 \\
\hline $60^{\circ}$ & 437.12 & 668.86 & 955.85 \\
\hline $90^{\circ}$ & 363.37 & 450.80 & 857.41 \\
\hline
\end{tabular}

\subsubsection{Characteristic analysis of impact current under different capacity of distribution transforms}

In the simulation, the power factor of low voltage of distribution transformer is 0.5 , and the experiment data are shown in Table 5. Table 5 shows that, under same closing angle and same distribution of distribution transforms, for different total distribution transform capacity, the closing impact current is different. The characteristic is represented as that under same closing angle, the higher total distribution transform capacity, the higher closing impact current is.

Table 5. The maximum peak of current under different capacity

\begin{tabular}{|c|c|c|c|c|}
\hline Impact current(A) & Closing angle $\left(^{\circ}\right)$ & $" 136 "$ & $" 334 "$ & $" 631 "$ \\
\hline 8MVA & 0 & 649.12 & 1000.3 & 1357.55 \\
\hline 4MVA & 0 & 408.28 & 744.18 & 972.05 \\
\hline 8MVA & 30 & 569.92 & 848.22 & 1224.90 \\
\hline 4MVA & 30 & 347.25 & 735.37 & 910.70 \\
\hline 8MVA & 60 & 437.12 & 668.86 & 955.85 \\
\hline 4MVA & 60 & 288.42 & 513.63 & 409.52 \\
\hline 8MVA & 90 & 363.37 & 450.80 & 857.41 \\
\hline 4MVA & 90 & 236.00 & 352.97 & 405.91 \\
\hline
\end{tabular}

\subsection{Analysis of Fall Time of Closing Impact Current}

On the basis of above studies, we select four typical lines with different distribution transformer capacity, under different closing angles, to analyze the needed time that closing impact current falls to selected current value.

(1)"631" distribution: 
Table 6. Fall time of impact current under "631" distribution

\begin{tabular}{|c|c|c|c|c|c|}
\hline \multicolumn{2}{|c|}{ Time(s) } & $4 \mathrm{M}$ & $6 \mathrm{M}$ & $8 \mathrm{M}$ & $10 \mathrm{M}$ \\
\hline $165 \mathrm{~A}$ & $231 \mathrm{~A}$ & 0.14 & 0.14 & 0.14 & 0.14 \\
\hline $220 \mathrm{~A}$ & $308 \mathrm{~A}$ & 0.1 & 0.1 & 0.1 & 0.1 \\
\hline $247 \mathrm{~A}$ & $346 \mathrm{~A}$ & - & 0.1 & 0.1 & 0.1 \\
\hline $330 \mathrm{~A}$ & $462 \mathrm{~A}$ & - & 0.08 & 0.06 & 0.06 \\
\hline $440 \mathrm{~A}$ & $616 \mathrm{~A}$ & - & - & 0.06 & 0.06 \\
\hline $412 \mathrm{~A}$ & $577 \mathrm{~A}$ & - & - & - & 0.06 \\
\hline $550 \mathrm{~A}$ & $770 \mathrm{~A}$ & - & - & - & 0.04 \\
\hline
\end{tabular}

(2)"136" distribution:

Table 7. Fall time of impact current under "136" distribution

\begin{tabular}{|c|c|c|c|c|c|}
\hline \multicolumn{2}{|c|}{ Time(s) } & $4 \mathrm{M}$ & $6 \mathrm{M}$ & $8 \mathrm{M}$ & $10 \mathrm{M}$ \\
\hline $165 \mathrm{~A}$ & $231 \mathrm{~A}$ & 0.04 & 0.06 & 0.06 & 0.08 \\
\hline $220 \mathrm{~A}$ & $308 \mathrm{~A}$ & 0.02 & 0.04 & 0.04 & 0.06 \\
\hline $247 \mathrm{~A}$ & $346 \mathrm{~A}$ & - & 0.04 & 0.04 & 0.06 \\
\hline $330 \mathrm{~A}$ & $462 \mathrm{~A}$ & - & 0.04 & 0.02 & 0.04 \\
\hline $440 \mathrm{~A}$ & $616 \mathrm{~A}$ & - & - & 0.02 & 0.02 \\
\hline $412 \mathrm{~A}$ & $577 \mathrm{~A}$ & - & - & - & 0.02 \\
\hline $550 \mathrm{~A}$ & $770 \mathrm{~A}$ & - & - & - & 0.02 \\
\hline
\end{tabular}

(3)"334" distribution:

Table 8. Fall time of impact current under "334" distribution

\begin{tabular}{|c|c|c|c|c|c|}
\hline \multicolumn{2}{|c|}{ Time(s) } & $4 \mathrm{M}$ & $6 \mathrm{M}$ & $8 \mathrm{M}$ & $10 \mathrm{M}$ \\
\hline $165 \mathrm{~A}$ & $231 \mathrm{~A}$ & 0.12 & 0.12 & 0.10 & 0.14 \\
\hline $220 \mathrm{~A}$ & $308 \mathrm{~A}$ & 0.08 & 0.10 & 0.06 & 0.10 \\
\hline $247 \mathrm{~A}$ & $346 \mathrm{~A}$ & - & 0.08 & 0.04 & 0.08 \\
\hline $330 \mathrm{~A}$ & $462 \mathrm{~A}$ & - & 0.06 & 0.04 & 0.06 \\
\hline $440 \mathrm{~A}$ & $616 \mathrm{~A}$ & - & - & 0.04 & 0.04 \\
\hline $412 \mathrm{~A}$ & $577 \mathrm{~A}$ & - & - & - & 0.04 \\
\hline $550 \mathrm{~A}$ & $770 \mathrm{~A}$ & - & - & - & 0.04 \\
\hline
\end{tabular}

(4)"361" distribution:

Table 9. Fall time of impact current under "361" distribution

\begin{tabular}{|c|c|c|c|c|c|}
\hline \multicolumn{2}{|c|}{ Time(s) } & $4 \mathrm{M}$ & $6 \mathrm{M}$ & $8 \mathrm{M}$ & $10 \mathrm{M}$ \\
\hline $165 \mathrm{~A}$ & $231 \mathrm{~A}$ & 0.12 & 0.12 & 0.12 & 0.14 \\
\hline $220 \mathrm{~A}$ & $308 \mathrm{~A}$ & 0.08 & 0.10 & 0.06 & 0.10 \\
\hline $247 \mathrm{~A}$ & $346 \mathrm{~A}$ & - & 0.08 & 0.06 & 0.06 \\
\hline $330 \mathrm{~A}$ & $462 \mathrm{~A}$ & - & 0.06 & 0.04 & 0.06 \\
\hline $440 \mathrm{~A}$ & $616 \mathrm{~A}$ & - & - & 0.04 & 0.04 \\
\hline $412 \mathrm{~A}$ & $577 \mathrm{~A}$ & - & - & - & 0.04 \\
\hline $550 \mathrm{~A}$ & $770 \mathrm{~A}$ & - & - & - & 0.04 \\
\hline
\end{tabular}

Explanation: in the above four tables (Table 6-9), the first column denotes the maximum load current value of the line; the second column denotes post-acceleration protection setting value, which is 1.4 times of maximum load current; the first row denotes different typical distribution transformer total capacity, where $4 \mathrm{M}$ denotes the total capacity of distribution transformer is $4 \mathrm{MW}$.

Through the simulation analysis of four typical lines, we find that there are some regular pattern of fall time of impact current under same capacity but different distribution, which is represented as that the higher capacity away from power source, the longer fall time of impact current is. 


\subsection{Structure of Closed-Loop Experiment System}

The closing post-acceleration protection of distribution network line is mainly influenced by closing impact current, and different distribution of distribution transformer capacity will influence the closing impact current.

The structure of test system is as shown in Figure 2:

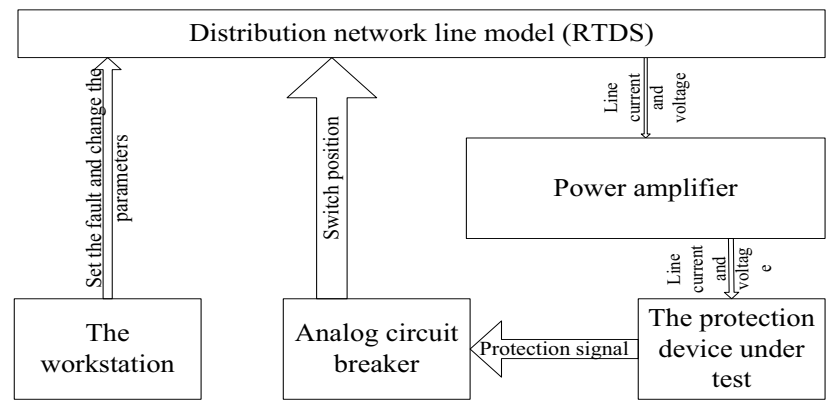

Figure 2. Structure of testing system

The real-time simulation model of distribution network line is established via parameters of unsuccessful reclosing to simulate the scene of unsuccessful reclosing when fault tripping. $10 \mathrm{kV}$ fault current (as shown in Figure 2) and voltage is output from RTDS, through the power amplifier and input to the protection device to be measured. Via simulating real-time change of CT and PT sampled values, fixed value setting is provided to the protection device, and a closed-loop test platform[8] of relay protection device for distribution network line is formed.

\subsection{Model Experimental Verification}

Real-time in-loop simulation system is built via the case line. Before the experiment, Setting parameters of line protective device are as follows: where the transformation ratio of protective device is 79.3 .

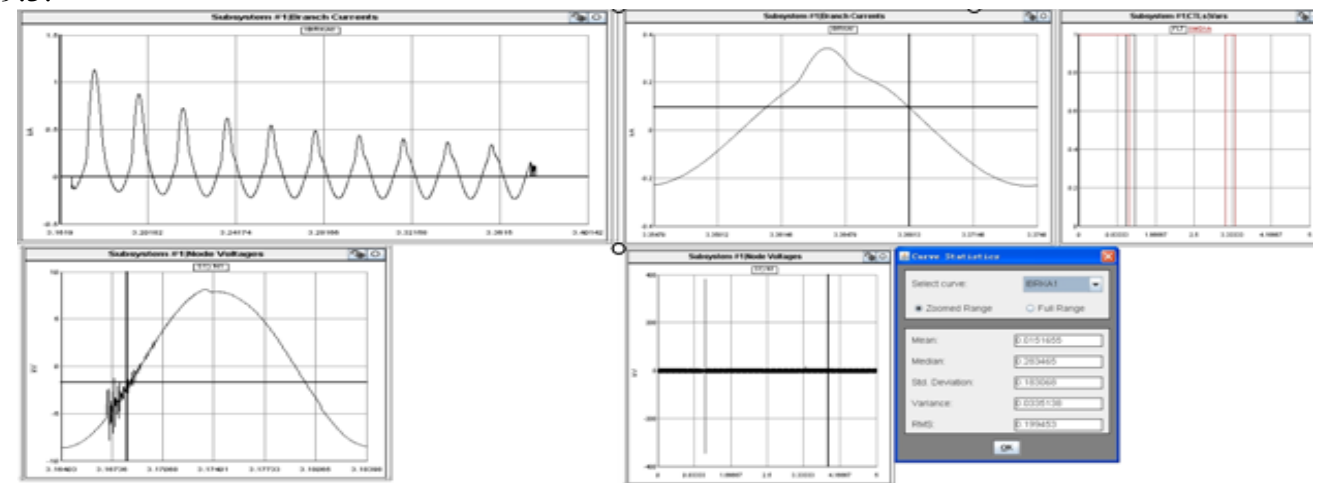

Figure 3. Structure of validation testing system

The field of unsuccessful closing of distribution network line in the case is simulated via the validation experiment of real-time in-loop simulation system model (Figure 3), and the model's reliability is verified.

\subsection{Post-acceleration setting time reference table}

When it is difficult to define which distribution the transmission line is, combined with analysis in section 3, the post-acceleration current setting is set as the maximum load current setting, the Postacceleration setting time reference table is as shown in Table 10. 
Table 10. Fall time of impact current under different setting value and different capacity

\begin{tabular}{|c|c|c|c|c|c|}
\hline \multicolumn{2}{|c|}{ Time(s) } & $4 \mathrm{M}$ & $6 \mathrm{M}$ & $8 \mathrm{M}$ & $10 \mathrm{M}$ \\
\hline $165 \mathrm{~A}$ & $231 \mathrm{~A}$ & 0.14 & 0.14 & 0.14 & 0.14 \\
\hline $220 \mathrm{~A}$ & $308 \mathrm{~A}$ & 0.10 & 0.10 & 0.10 & 0.10 \\
\hline $247 \mathrm{~A}$ & $346 \mathrm{~A}$ & - & 0.10 & 0.10 & 0.10 \\
\hline $330 \mathrm{~A}$ & $462 \mathrm{~A}$ & - & 0.08 & 0.06 & 0.06 \\
\hline $440 \mathrm{~A}$ & $616 \mathrm{~A}$ & - & - & 0.06 & 0.06 \\
\hline $412 \mathrm{~A}$ & $577 \mathrm{~A}$ & - & - & - & 0.06 \\
\hline $550 \mathrm{~A}$ & $770 \mathrm{~A}$ & - & - & - & 0.04 \\
\hline
\end{tabular}

\section{Conclusions}

In this paper, a distribution network line reclosing simulation model is established based on real-time digital simulation technology. Through packaging design of submodule, the advantages of RTDS modeling, such as expansibility and easy to be used in closed-loop test, are made good use. The realtime simulation experiment platform is established, then on this base, characteristics of reclosing impact current under different distribution transformer capacity distribution and different operation mode are researched, and magnetizing rush current fall time reference table under four typical capacity distribution is proposed, which provide the basis for post-acceleration setting of distribution network line relay protection device, ensure the protection device to avoid the magnetizing rush current and mistrip, and improve the success rate of distribution network line reclosing and the power supply reliability.

\section{References}

1. Lü Li-ting, Luo Jian, Huang Zheng-xuan, Ou Zu-guo, Simulation and analysis of the inrush of power transformer, Relay, $\mathbf{0 5}(2007)$

2. Hao Zhi-guo, Zhang Bao-hui, Chu Yun-long, Trend and Situation of Distinguish Technology of Transformer Magnetizing Inrush Current J, Transformer, 07(2005)

3. Huang Fengpin, Exploration on Protection Setting Coordination of $10 \mathrm{kV}$ Distribution Lines J, Guangdong science \&technology, 20(2011)

4. Ma Enda, Computation of Protection Setting Coordination of $10 \mathrm{kV}$ Distribution Lines, Science \&technology information, 09(2012)

5. Chen Jia-lin, Brief analysis setting calculation and application of $10 \mathrm{kV}$ overhead line protection,Science \&technology information, 28(2006)

6. Liang Zhi-chen, Ma Xian-dong, Wang Like, KuffelR, Jiang Xiao, Realtime digital simulator RTDS and its application, Automation of electric power Systems, 10(1997)

7. Suonan Jia-le, Kang Xiao-ning, Song Guo-bing, Jiao Zai-bin, Yun Bao-ji, Survey on Relay Protection Using Parameter Identification, Proceedings of the electric power system and automation,01(2007)

8. Zhou Wei, Zhang Pei-chao, Yang Xing-xing, A real-time closed-loop digital simulation system for computer protections based on RTDS, Power system protection and control,16(2010) 